\title{
The Case of "Rosa": AEDP in the Realm of Cultural Diversity- One's New Language as a Vehicle for Exploring New Aspects of Identity
}

\section{HUAN JACQUIE YE-PERMAN ${ }^{\mathrm{a}, \mathrm{b}}$}

\author{
${ }^{a}$ The AEDP Institute, New York, NY \\ ${ }^{\mathrm{b}}$ Correspondence regarding this article should be sent to Huan Jacquie Ye-Perman, 1616 8th Ave, 1616 8th Ave, \\ Grinnell, IA 50112. \\ Email: drhjperman@gmail.com
}

\begin{abstract}
Vigoda Gonzalez's (2018) case study provides an excellent illustration of how AEDP leads to deep and effective treatment for a client with attachment trauma, leading not only to significant symptom reduction but also to profound change for the better. In this review, I provide additional observations and analysis of AEDP as reflected in this case, both in terms of specific interventions and the phenomenology of transformation. From the practice of multiculturalism in psychotherapy, I also highlight Vigoda Gonzalez's bi-linguistic ability and bi-cultural background as facilitative for the therapy process. I examine the various factors that play into the impact of ethnicity/language-matching, and suggest that the lack of such matching is by no means an automatic hindrance for the therapy process. Similarly a client's choosing to speak in a language not native to them in therapy can be a vehicle for the exploration of new experiences, and new aspects of self. It is my belief that what is most important is for the culturally sensitive therapist to actively explore different means of communication within and beyond the boundaries of language, thus staying closely attuned to the client's emotional experiences.
\end{abstract}

Key Words: psychotherapy; attachment; trauma; AEDP; culture; bi-lingualism; case study; clinical case study

\section{INTRODUCTION}

It was a pleasure for me to witness in writing how effectively Nicole Vigoda Gonzalez (2018) utilized Accelerated Experiential Dynamic Psychotherapy (AEDP) to meet her client Rosa's need for a good relational experience and to process her attachment trauma-related emotions. It was reassuring to read how Vigoda Gonzalez used her own bilingualism to open an additional venue of communication to match Rosa's needs, and deeply moving to witness Rosa's experiencing, throughout the course of the therapy, the phenomenon of profound change (Fosha, 2017). 
One's New Language as a Vehicle for Exploring New Aspects of Identity

H.J. Ye-Perman

Pragmatic Case Studies in Psychotherapy, http://pcsp.libraries.rutgers.edu

Volume 14, Module 2, Article 5, pp. 147-157, 12-14-18 [copyright by author]

In this review, I aim to highlight how Vigoda Gonzalez's work reveals AEDP to be an ideal treatment choice for clients with attachment trauma because of its focus on experiential processing within the therapeutic dyad. I also will explore how shared languages and a matching of bicultural identities between therapist and client clearly benefitted Rosa's treatment. Vigoda Gonzalez's paper raises an important question, though: how can therapists maximize their cultural competence and make good use of AEDP if they do not speak the client's mother tongue? I will consider this challenge by drawing on my past research and clinical experience, highlighting the ways in which AEDP's versatility has allowed me to be available and culturally sensitive with clients, even in the many cases when their linguistic and cultural backgrounds are different from mine.

An important backdrop to my commentary is my own personal experience as a bilingual, bi-cultural psychotherapist navigating in the psychotherapy world. This is described in the first article in this section by Fosha (2018a). Let me add here that in recent years, I have brought AEDP methods to the Chinese therapeutic community in China: translating AEDP papers and constructs into Chinese, teaching and supervising AEDP, and providing AEDP therapy in Chinese. With this growing experience, with surprise and delight I am further convinced that AEDP is highly adaptable across cultures, and this commentary will identify some factors that I believe make it so. Furthermore, I have also discovered my increased sense of comfort and flexibility in working with clients grappling with cultural identity issues and acculturation, and I have integrated my professional, adult identity with my Chinese being.

\section{VIGODA GONZALEZ'S SWITCH TO AEDP WITH ROSA}

Vigoda Gonzalez began treating Rosa with Intensive Short Term Dynamic Psychotherapy (Davanloo, 1980). She soon noticed that, instead of "dropping down" into her core affects, the client was ramping up her defenses and disconnecting from her experience, a sure sign that her felt sense of therapeutic safety was insufficient for deeper work. AEDP is designed precisely to facilitate a treatment environment that allows for a softening of defenses, a reduction of anxiety, and a deepened access to emotional experience; unsurprisingly, Vigoda Gonzalez's change of approach to AEDP was fruitful.

Consistent with AEDP's principles (Fosha, 2000), Vigoda Gonzalez effectively attuned to Rosa's indirect feedback (her rejection of their initial process) and used it to guide the next phase of treatment. Rosa, in turn, felt a new sense of safety and began opening up to her difficult emotions. This can be interpreted from an attachment standpoint as reflecting a process of relational repair and rupture, which AEDP understands to be key in forging a stronger and more resilient therapist-client relationship (Fosha, 2000; Tronick, 2009).

Indeed, as Vigoda Gonzalez reflected, a secure attachment experience needed to be at the very heart of the work with Rosa, whose significant trauma history involved repeated emotionally aversive experiences. As Rosa became more deeply trusting of and attached to her therapist - who was unquestionably attuned, affirming, and positively emotionally regulatedshe increasingly revealed her previously hidden authentic self, increasingly dared to explore new 
One's New Language as a Vehicle for Exploring New Aspects of Identity

H.J. Ye-Perman

Pragmatic Case Studies in Psychotherapy, http://pcsp.libraries.rutgers.edu

Volume 14, Module 2, Article 5, pp. 147-157, 12-14-18 [copyright by author]

areas of experience, and emerged from the completed therapy quite strikingly as a wellfunctioning, healthy, emotional, relatable, flexible, and compassionate woman. This case study epitomizes Fosha's (2004) assertion that it is the "goodness" of the experience that an AEDP therapist provides a client that signifies the change process in action (Gendlin, 1981, 1996; Levine, 1997).

\section{THE PHENOMENA OF TRANSFORMATION AT AN EXEMPLARY MOMENT IN ROSA'S CASE}

At the outset of treatment, Vigoda Gonzalez accurately recognized Rosa's attachment trauma as the root of her emotional distress. Persistent experiences of being put down and shut out by her family members - the very people one looks to for safety and support - had corrosive effects on Rosa's sense of self and way of being, compromising her capacity to deal with emotional distress and subsequent life stressors. AEDP recognizes the power of trauma work in opening individuals to transformation and spells out the conditions necessary to harness this power towards transformational change, i.e., change for the better (Fosha, 2002, 2014). Adhering to these conditions, Vigoda Gonzalez was consistently attuned to Rosa while assisting her in processing past emotional pains. Ultimately Rosa was able to release her transformance drive (Fosha, 2008) towards growth and the authentic self.

A seminal moment deserving more attention and exploration than is in Vigoda Gonzalez's case srudy occurs in session 4, when she says: "You have put so much effort into being noticed, accepted, and nurtured, and despite all of your efforts, you end up feeling berated, bullied, and targeted by others" (p. 26). Zooming in, we can see that the effect of this intervention is two-fold. In tears, Rosa replied: "I couldn't have said it better" (p. 26).

First, being presented with an accurate and empathic reflection of her own emotional experience, Rosa's aloneness was undone, and she experienced a moment of fresh selfrecognition. It was a positive affective and relational experience. Her tears may have contained both sadness as a mourning-of-the-self, as well as the joy of being recognized expressed in the healing affects (Fosha, 2007).

Second, Vigoda Gonzalez's statement provided a new angle to Rosa's narrative: While Rosa had felt stuck for years in the role of a passive and powerless victim, her therapist recognized and mirrored to her that there was also a part of her that all along had been an active agent working for positive growth. Rosa's sense of worthiness, her intuition about what's good for her, and her longing of "being noticed, accepted, and nurtured" had all been preserved despite her overwhelmingly hindering environment. "I wanna move past that!" (p. 26) she exclaimed in that moment. In response to the wonderful example of Vigoda's Gonzales' comment reflecting transformance detection, what strongly comes forth from Rosa is the voice of her resilience, her adaptive action tendencies, her "neurobiological core self," which came to life when it was seen by a knowing other (Fosha, 2013). 
One's New Language as a Vehicle for Exploring New Aspects of Identity

H.J. Ye-Perman

Pragmatic Case Studies in Psychotherapy, http://pcsp.libraries.rutgers.edu

Volume 14, Module 2, Article 5, pp. 147-157, 12-14-18 [copyright by author]

One of AEDP's most important tools to expand a client's transformation is metatherapeutic processing (metaprocessing, for short), where "affect and cognition come together and meaning is created" (Russell \& Fosha, 2008, p. 171). By tracking the distinctive somatic affective markers that identify the transformational process, the AEDP therapist can bring to awareness new emotional experiences that might otherwise remain unnoticed (Fosha, 2000, 2017). This awareness, in turn, can subsequently catalyze another wave of profound and expansive transformation.

One important component evident in this case is the AEDP State 3 Transformational Affects phenomena, a more recent elaboration to Fosha's original model (Fosha, 2009). In State 3 , a client experiences a new wave of "heralding affects," trembling in sensation and positive at the core. If recognized, regulated, and processed sufficiently, according to the AEDP model, these State 3 affects lead to State 4 Core State. (For more on this topic as it relates to the case of Rosa, see Fosha, 2018b).

Viewing Rosa's case through an AEDP lens, we see that Vigoda Gonzalez's approach helped Rosa (i) regulate her anxiety, (ii) put aside State 1 defenses in response to sufficient relational safety, and (iii) launch into State 2 processing of previously intolerable emotional pain from past trauma, i.e., "feeling and dealing while relating" in secure attachment (Fosha, 2000; Pando-Mars, 2016). Rosa clearly was receptive to the new perspective of her own strength that her therapist offered her. Her intact self - the manifestations of transformance - was seen, known, and valued by a trusted other; and Rosa then experienced a wave of positive affects including relief, hope, bravery, and authenticity (Fosha, 2012). Additionally, Rosa evidenced State 3 transformational affects, including the mastery affects of pride and joy, the grieving tears associated with mourning-of-the self, the joyful tears of the healing affects of being moved, and gratitude towards self-affirmation, as well as the realization affects associated with the new understanding of the self.

While such metaprocessing was not explicitly noted in Vigoda Gonzalez's case study, it is evident upon close examination (again see Fosha, 2018b). As her therapy progressed, Rosa's receptive affective capacity of the internal and interpersonal positive affects clearly expanded, evidenced by her increasing receptivity to Vigoda Gonzalez's affirmation. For example, in Session 16, Vigoda Gonzalez invited Rosa to metaprocess, and Rosa, in response, discovered how her transformation occurred both internally and interpersonally, as recorded in Vigoda Gonzalez's case study. Rosa's positive affective experiences were consolidated, and their spiraling effects released (Fosha, 2007).

\section{LANGUAGE COMMUNICATION IN AEDP}

Psychotherapists long have observed the significance of language in trauma healing. For instance, Freud (1893) encouraged his patient to describe traumatic events with as much great detail as possible, and Herman (1992) proposed a model of trauma treatment in which the mindful use of language is embedded in each step of recovery. Rosa had lived in an Englishspeaking culture since age three and spoke English fluently, but many of the fraught family-of- 
One's New Language as a Vehicle for Exploring New Aspects of Identity

H.J. Ye-Perman

Pragmatic Case Studies in Psychotherapy, http://pcsp.libraries.rutgers.edu

Volume 14, Module 2, Article 5, pp. 147-157, 12-14-18 [copyright by author]

origin experiences that engendered her present emotional struggles had occurred in the Spanish language. It is most natural then that throughout her treatment, Rosa uses Spanish when processing her early trauma, and fortunately Vigoda Gonzalez was able to join her, hence maximizing their dyadic communication within the boundaries of language, in this case, two languages. Conversely, Rosa usually expressed her present moment experiences, often associated with positive affect and her experiences of change-for-the-better in English. It was as if her mother-tongue, Spanish was the language of both child and trauma, while English became not only the adult language, but perhaps the language of resilience and even transformation.

In her unrelenting availability for Rosa and willingness to engage with her in Spanishin response to which Rosa expressed palpable delight - Vigoda Gonzalez epitomizes the available and responsive attachment figure, the hallmark of AEDP (Fosha, 2012). Bilingualism allowed her yet another way in which to help undo Rosa's aloneness (Fosha, 2000, 2013), and to accompany Rosa in facing and processing what had been such feared and previously disorganizing emotions. Vigoda Gonzalez communicated that she would be there for Rosa however she wished to relay her emotions linguistically. Her use of Spanish was far more than a communicational convenience; it was a therapeutic message to Rosa that she will not need to face a flood of trauma memories or explore positive new experiences alone. She would finally have sufficient support to stay regulated, and not need to resort to avoidance or dissociation. Indeed, as Vigoda Gonzalez outlines in her case, in the comfort of this newly emergent secure attachment, Rosa could increasingly_in the words of Fosha (2000, p. 42)—_feel," "deal," and "relate."

Rosa's language patterns remind me of "L.," a bilingual client of mine. L. is an international graduate student from China whose mother tongue is Chinese and who speaks English with moderate fluency. Though he knew that I speak Chinese, from the outset L. chose to communicate with me in English, except when he could not find a proper English equivalent for a word. At one point later in our treatment, I asked L. about this language choice that he had made. He reflected that English made it easier to explore his romantic affair with another student who was married. If he spoke in Chinese about his love and emotional pain, he would be overwhelmed with the cultural stigma and shame associated with extra-marital relationships. He also explained that he felt less awkward speaking about love in English, partly due to the English vocabulary he could use. In other words, by using English L. gained new freedom to access deeper and more personal emotional truths.

Similarly, when I was a client with my mono-lingual English-speaking therapists, I found it relatively easy to use English to process early negative emotions that I experienced with my family. Part of the reason was that I experienced myself as behaving consistently with mainstream Western culture, in being open to speak negatively of one's parents and actively separating my individual identity from family. In contrast, speaking negatively about one's family can be considered a major offense to the value of "piety" in Chinese culture, and a departure from the cultural identity. 
One's New Language as a Vehicle for Exploring New Aspects of Identity

H.J. Ye-Perman

Pragmatic Case Studies in Psychotherapy, http://pcsp.libraries.rutgers.edu

Volume 14, Module 2, Article 5, pp. 147-157, 12-14-18 [copyright by author]

Along these lines, it is possible that a bi- or multi-lingual client may adopt two or more cultural identities in treatment, each associated with a distinct system of values and behavioral norms. I have often witnessed clients negotiate multiple identities in treatment; I assist them in being more conscious about how and when they shift adherence to each cultural system. I find that such flexible identity alignment, chosen reflectively, can be an incredible resource for a client. Often, for instance, one identity in a particular context can be associated with strength and resourcefulness while another with helplessness and shame. Facilitating this adaptive identity alignment is akin to what we do in an AEDP reparative portrayal when we elicit help from the "adult self" for the "child self," or when we seek to engage the self-at-best in order to be able to work with the self-at-worst (Fosha, 2000).

\section{ETHNICITY-MATCHING: A FURTHER EXAMINATION}

In light of the therapist's cultural competence and the benefits of ethnic-matching in the case of Rosa, I would like to bring three relevant variables to the forefront and discuss their implications for the benefits of ethnic-matching: one's racial/minority status, level of acculturation, and ethnic identity. The first one was examined to some extent in Vigoda Gonzalez's case study, while the other two were unexplored.

First, whether someone has minority status, and the extent to which such status shapes their experiences of safety and determines their risk of discrimination, tends to contribute to their level of trust towards other individuals in relation to the minority status. Note that the concept "race" is relevant here because it captures one's historical-social-political position in a given societal system, i.e., one's minority or non-minority status. Race is a social construct that can overlap with ethnicity, but can also be distinctively different, as the latter refers to a common tradition of shared values and customs to which individuals relate as part of their identity (Delgado-Romero et al., 2005).

Second, acculturation level is defined as an individual's levels of identification with the host culture and home culture (Berry, et al., 1987). It is a fluid variable, associated with one's sense of self and the way the individual relates to others in a given cultural context.

Finally, individuals' sense of ethnic identity, as part of self-identity, is also a fluid, individual, and partly self-directed experience, rather than a stagnant, fixed, categorical variable and one solely or automatically defined by one's ethnic background (Phinney \& Ong, 2007). Indeed, Miller (2007) measured individuals' sense of belongingness and their degrees of adherence to specific values and behaviors of their corresponding ethnic groups, and found there was a wide range of individual variation.

Rosa had been a victim of racism, which was part of her relational trauma. Knowing that Vigoda Gonzalez shared a similar cultural affiliation made it easier for Rosa to disclose the trauma associated with her ethnic membership. Indeed, Ward (2005) found from his sample of African American clients that the enhancement of a counselor's effectiveness based on race was only true for those clients who had a salient Black identity associated their sense of safety. Of 
One's New Language as a Vehicle for Exploring New Aspects of Identity

H.J. Ye-Perman

Pragmatic Case Studies in Psychotherapy, http://pcsp.libraries.rutgers.edu

Volume 14, Module 2, Article 5, pp. 147-157, 12-14-18 [copyright by author]

course, shared racial identity/ethnicity is no guarantee for protection from racial prejudice, for within-group racism and internalized racism towards one's self is not uncommon. As a case in point: Rosa was a target of her family members' racism. This is something that was not explored in Vigoda Gonzalez's paper and possibly not in the treatment: both might have benefitted from attention to this issue.

Both clients' and therapists' own ethnic/racial identities and acculturational levels are likely to impact the benefits of ethnic/racial matching. The therapist needs to be sensitive to a client's sense of cultural identities and acculturation levels, and the possible shift of those variables within an individual over time. Moreover, the therapist should strive to be aware of her/his own bias towards her/his own and others' ethnic groups, and be open to work through the impact of such bias on the therapy process. In Rosa's case, it is unclear to what extent Rosa had assumed and/or experienced similarities with Vigoda Gonzalez in regard to ethnicity based on what she termed and confirmed by Vigoda Gonzalez as shared "Spanish background." This assumed sharing is also complicated by the fact that Spanish-speaking communities contain many distinctively different cultures. One thing is clear, nonetheless. In this case, both client and therapist were individuals with bi-cultural affiliations, which clearly contributed to their bonding, certainly Rosa's to her therapist (Vigoda Gonzalez does not self-disclose how the shared language and cultural affiliation affected her and her feelings toward her client).

When discussing the practice of cultural competence in trauma treatment, Brown (2008) called for therapists to strive to understand how the cultural context and the individual's identity had added meanings for a client's trauma experience. She urges therapists to obtain the relevant knowledge and skills, and once actualized, make such availability explicit to the client. Brown (2008) advocated that, in the case when the therapist does not speak the client's mother tongue, the therapist should still encourage the client to speak their mother-tongue, whenever the client feels so inclined. In that way, the client has the experience of expressing the thoughts and feelings, and the therapist can gain non-verbal understanding by witnessing the client's body language, working on linguistic understanding by seeking for translation and paraphrasing from the client afterwards.

The variables of culture and minority status extend beyond ethnicity to other dimensions of human characteristics, such as gender, sexual orientation, socio-economic backgrounds, country of origin, body able-ness, educational levels, spirituality, and age. A culturally competent therapist should consider all the above factors in the effort to establish optimal therapeutic safety and connection for each client. This effort is congruent with AEDP's practice. In AEDP it is considered important that therapists not be dogmatic about any specific technique, but rather experiment with various methods, the goal being discovering the best way of assisting this client in this moment in moving forward in their transformational therapeutic journey (Fosha, 2000). 
One's New Language as a Vehicle for Exploring New Aspects of Identity

H.J. Ye-Perman

Pragmatic Case Studies in Psychotherapy, http://pcsp.libraries.rutgers.edu

Volume 14, Module 2, Article 5, pp. 147-157, 12-14-18 [copyright by author]

\section{AEDP FOR TRAUMA TREATMENT: BEYOND LANGUAGE}

The past two decades of advances in affective neuroscience (Panksepp, 2009; Porges, 2011; Schore, 2012; Siegel, 2003) have shed light on the process of psychotherapy as more a right-brain to right-brain and limbic-system to limbic-system exchange between client and therapist, rather than what was historically believed to be a dominantly left-brain linguistic activity, reflected by the term "talk therapy." As summarized by Schore (2012, p. 39), "implicit right brain-to-right brain intersubjective transactions lie at the core of the therapeutic relationship." This is particularly crucial for individuals suffering from attachment trauma and PTSD. As van der Kolk observed, by their nature, "traumatic events are almost impossible to put into words" (2014, p. 233). In the wake of the intense shock to our nervous system from the traumatic event, and the excruciatingly painful discovery that we are left alone to cope with such unbearable experience, absent the opportunity to process the traumatic experiences, we end up with functioning that is dominated either by the over-activated sympathetic autonomic nervous reaction of fight or flight, or by the shutdown of the dorsal vagal parasympathetic response we observe in the reactions of collapse, freeze, numbing or disassociation (see Porges, 2011). A split, or a disassociation occurred in our self-experience between, on the one hand, our limbic system and related right-brain functions managing the emotions associated with the trauma experience, and on the other hand, our left-brain functioning self-managing the challenges of day-to-day life.

Indeed, with trauma, what was lost in words was not lost in the body (van der Kolk, 2014). By tracking the body, identifying somatic markers, we can recover and invite words to match the experience, thus working to "make the implicit explicit" (Fosha, 2012). Specifically in AEDP, we seek to first facilitate the client's having experience "in which the body must be involved" (van der Kolk, 2014), and we do so "through tracking moment-to-moment fluctuations in the emotional experience of patient, therapist, and dyad" (Fosha, 2012). We track our clients' somatic reactions for any cues that the previously excluded emotional experiences are back online in response to the safe therapeutic environment being co-created. We detect those cues and assist the clients to further bring those experiences into awareness, regulate and organize them with our guidance and support (Fosha, 2013). When the emotions are regulated and processed, allowing them to be an integrated in a genuine sense of self, we seek for the subsequent body cues of vitality and experientially metaprocess them, seeking to amplify them. This is precisely the experience of "invigorated," as mentioned several times by Rosa during the latter part of the treatment.

In my personal experiences of utilizing AEDP and teaching AEDP in cross-cultural context, the focus on and tracking of affect and other aspects of non-verbal experience allows AEDP to be especially adaptable to other cultural contexts, including when the therapist doesn't share the same language and/or cultural background as the client. The reaction of our nervous systems in face of danger versus safety seems to be more universal than language expression, although not without cultural differences even in that realm. 
One's New Language as a Vehicle for Exploring New Aspects of Identity

H.J. Ye-Perman

Pragmatic Case Studies in Psychotherapy, http://pcsp.libraries.rutgers.edu

Volume 14, Module 2, Article 5, pp. 147-157, 12-14-18 [copyright by author]

It is fortunate when a therapist can engage in the client's preferred mode of language communication, as Vigoda Gonzalez was able to do for Rosa. However, whether or not the therapist speaks the client's mother tongue, it is of paramount importance for the therapist to keep track of the client's sensations, tone of voice, body tensions and shifts, and so forth that are essential aspects of the client's emotional process regardless of what language is being spoken (Fosha, 2000). As Mars (2011) points out, the therapist can also track to the client's non-verbal behaviors Mindell's (1985) seven channels of experiences: sensation, emotion, energetic awareness, movement, auditory, visual, and imagery.

Moment-to-moment tracking of the client's fluctuations in one or more of these realms can allow emotional access to areas of emotional experience that are not captured in language. After all, in any given human communication, $90 \%$ of the exchange is likely to occur in the nonverbal domain (Goleman, 2006). The therapist can also encourage the client to search for other methods of expression outside language, for instance in dance, in music, and in the arts; and thus the therapist can be available to clients' communication through these additional right-brain means. Such means of communication can further deepen emotional experiences, hence potentially leading to another wave of productive therapy work (Fosha, 2012).

\section{REFERENCES}

Berry, J.W., Kim, U., Minde, T., \& Mok, D. (1987). Comparative studies of acculturative stress International Migration Review, 21(3), 491-511.

Breuer, J., and Freud, S. (1893). "The physical mechanisms of hysterical phenomena," in The standard edition of the complete psychological works of Sigmund Freud. London: Hogarth Press,.

Brown, Laura S. (2008). Cultural competence in trauma therapy: Beyond the flashback. Washington, DC: American Psychological Association.

Davanloo, H. (Ed.). (1980). Short-term dynamic psychotherapy. New York: Jason Aronson.

Delgado-Romero, E. A., Galván N., Maschino, P., and Rowland M. (2005). Race and ethnicity in empirical counseling and counseling psychology research: A 10-year review. The Counseling Psychologist, 33, 419-448.

Fosha, D. (2000). The transforming power of affect: A model for accelerated change. New York: Basic Books.

Fosha, D. (2002). Trauma reveals the roots of resilience. Constructivism in the Human Sciences, 6 (1\&2), 7-15. Special September $11^{\text {th }}$ issue.

Fosha, D. (2004). "Nothing that feels bad is ever the last step": The role of positive emotions in experiential work with difficult emotional experiences. Clinical Psychology and Psychotherapy, 11, 30-43.

Fosha, D. (2007). "Good spiraling": The phenomenology of healing and the engendering of secure attachment in AEDP. The Gains Quarterly: Connections \& Reflections, Summer.

Fosha D. (2009). Emotion and recognition at work: Energy, vitality, pleasure, truth, desire \& the emergent phenomenology of transformational experience. In D. Fosha, D. J. Siegel \& M. 
One's New Language as a Vehicle for Exploring New Aspects of Identity

H.J. Ye-Perman

Pragmatic Case Studies in Psychotherapy, http://pcsp.libraries.rutgers.edu

Volume 14, Module 2, Article 5, pp. 147-157, 12-14-18 [copyright by author]

F. Solomon (Eds.), The healing power of emotion: Affective neuroscience, development, clinical practice. Chapter 7. New York: Norton.

Fosha, D. (2012). Proceeding for EFT Summit 2012: AEDP at Work Growing Receptive Affective Capacity to Repair \& Transform Attachment Trauma. New York.

Fosha, D. (2013). A heaven in a wild flower: Self, dissociation, and treatment in the context of the neurobiological core self. Psychoanalytic Inquiry: A Topical Journal for Mental Health Professionals, 33(5), 496-523.

Gendlin, E. T. (1981). Focusing. New York: Bantam New Age Paperbacks.

Gendlin, E. T. (1996). Focusing-oriented psychotherapy: A manual of the experiential method. New York: Guilford.

Goleman, D. (2006). Social intelligence: The new science of human relationships. New York: Random House Digital.

Herman, J. (1992). Trauma and recovery: The aftermath of violence-from domestic abuse to political terror. New York: Basic Books.

Levine, P. (1997). Waking the tiger: Healing trauma. Berkeley, CA: North Atlantic Books.

Mars, D. (2011). AEDP for couples: From stuckness and reactivity to the felt experience of love. Transformance: The AEDP Journal, 2(1).

Mindell, A. (1985). Working with the dreaming body. London: Routledge and Kegan.

Miller, M. J. (2007). A bilinear multidimensional measurement model of Asian American acculturation and enculturation: Implications for counseling interventions. Journal of Counseling Psychology, 54, 118-131.

Pando-Mars, K. (2016). Tailoring AEDP interventions to attachment style. Transformance: The AEDP Journal 5(1).

Panksepp, J. (2009). Brain emotional systems and qualities of mental life: From animal models of affect to implications for psychotherapeutics. In D. Fosha, D. J. Siegel \& M. F.

Solomon (Eds.), The healing power of emotion: Affective neuroscience, development, clinical practice. Chapter 1. New York: Norton.

Parham, T.A., \& Helms, J.E. (1981). The influence of black students' racial identity attitudes on preferences for counselor's race. Journal of Counseling Psychology, 28, 250-257.

Phinney, J. S., \& Ong, A. D. (2007). Conceptualization and measurement of ethnic identity: Current status and future directions. Journal of Counseling Psychology, 54(3), 271-281.

Porges, S. W. (2011). The Polyvagal theory: Neurophysiological foundations of emotions, attachment, communication, and self-regulation. New York: W. W. Norton \& Company.

Prenn, N. C. N. \& Fosha, D. (2017) Supervision essentials for Accelerated Experiential Dynamic Psychotherapy. Washington, DC: American Psychological Association.

Russell, E., \& Fosha, D. (2008). Transformational affects and core state in AEDP: The emergence and consolidation of joy, hope, gratitude, and confidence in (the solid goodness of) the self. Journal of Psychotherapy Integration, 18(2), 167-190.

Schore, A. (2012). The Science of the art of psychotherapy. New York, NY: W. W. Norton \& Company, Inc.

Siegel, D. J. (2003). An interpersonal neurobiology of psychotherapy: The developing mind and the resolution of trauma. In M. F. Solomon \& D. J. Siegel (Eds.), Healing trauma: Attachment, trauma, the brain and the mind (pp. 1-54). New York: Norton. 
Tronick, E. (2009). Multilevel meaning making and dyadic expansion of consciousness theory: The emotional and the polymorphic polysemic flow of meaning. In D. Fosha, D. J. Siegel \& M. F. Solomon (Eds.), The healing power of emotion: Affective neuroscience, development, clinical practice. Chapter 4. New York: Norton.

Van der Kolk, B. A. (2014). The body keeps the score: Brain, mind, and body in the healing of trauma. New York: Penguin Books.

Vigoda Gonzales, N. (2018). The merits of integrating accelerated experiential dynamic psychotherapy and cultural competence strategies in the treatment of relational trauma: The case of "Rosa. Pragmatic Case Studies in Psychotherapy, 14(1), Article 1, 1-57. Available: http://pcsp.libraries.rutgers.edu. http://dx.doi.org/10.14713/pcsp.v14i1.2032

Ward, E. C. (2005). Keeping it real: A grounded theory study of African American clients engaging in counseling at a community mental health agency. Journal of Counseling Psychology, 52(4), 471-481. 